\title{
LIGHT FIDELITY (LI-FI) OVERVIEW AND INVESTIGATION INTO CONNECTION SPEED
}

\author{
MITHUN SHARMA ${ }^{\circledR}$ SHILPI SHARMA
}

\begin{abstract}
A B S T R A C T
The overarching aim was to reduce the frequency of connection failures that occur due to the connection speed and reliability, and identify, characterise and optimise the key process input variables (KPIVs). An experimental research approach with an inbuilt planned manipulation to one or more variables in the experimental data set was adopted. Key elements of the Six-Sigma methodology were applied to resolve the issue of high failures due to connection speed and reliability between two Li-Fi transceivers. KPIVs were successfully identified, characterised and optimised to implement a permanent corrective action to ensure a reduction in connection failures from $17 \%$ to $0 \%$. The alignment between two Li-Fi transceivers along with Li-Fi cut-out was found to be critical in achieving good connection speed and reliability. The interference due to ambient visible spectrum lighting found to be statistically insignificant. This study explored the application and benefits of accessible wireless data communication technologies. Moreover, it sheds light on the probable factors that may influence Li-Fi connection speed and areas for future research. The current research provides a SixSigma based solution to high connection failure rates while using an infrared-based $\mathrm{Li}$-Fi transceiver. Results also offer insights into the analytical tools that were found to be effective during the problem-solving process.
\end{abstract}

KEY WORDS

Light Fidelity (Li-Fi), Six-Sigma, defect reduction, wireless communication

10.2478/emj-2021-0005
Mithun Sharma

O.P. Jindal Global University, India ORCID 0000-0002-0108-6331

Corresponding author: e-mail: mithun.sharma@gmail.com

Shilpi Sharma

O.P. Jindal Global University, India ORCID 0000-0003-4316-8551

\section{INTRODUCTION}

Over the past decade, the demand for digital services has grown at an astonishing pace, with the number of worldwide Internet users burgeoning significantly. The demand for data and digital services is also expected to grow exponentially, with global Internet traffic doubling by 2022 to 4.2 zettabytes per year. The number of mobile internet users is projected to increase from 3.8 billion in 2019 to 5 billion by 2025, and the volume of Internet of Things (IoT) con-

Sharma, M., \& Sharma, S. (2021). Light Fidelity (Li-Fi) overview and investigation into connection speed. Engineering Management in Production and Services, 13(1), 63-73. doi: 10.2478/emj-2021-0005 
nections (interconnected physical objects via the Internet) is expected to double from 12 billion to 25 billion (Cisco, 2019). These changes are driving exponential growth in the demand for data centre and network services (Sumits, 2015). The currently available radio spectrum is below $10 \mathrm{GHz}$ (cm-wave communication), which is insufficient to deal with the demands arising out of these mounting changes and is thus put under severe strain. To deal with this constraint, the wireless communication industry is forced to explore alternative options that are beyond the range of radio spectrum, in particular infrared and visible light spectrums (Tsonev, Videv \& Haas, 2013).

One such possible substitute and an emerging Visible Light Communication technology is LightFidelity (Li-Fi) that allows wireless transfer of data at high speeds through visible light, ultraviolet and infrared spectrums. The underpinning principle is simple. It relies on the speed of the transmitter modulator that switches a light-emitting diode (LED) on and off so quickly that it is undetectable by the human eye (Hass, 2018). A photodiode on the receiver picks up the light and converts it into electrical impulses. The study presented in this article explores the application of Li-Fi when communicating with Automated Guided Vehicles (AGV) wirelessly. Previously, AGV were connected via Wi-Fi communication technologies with the vehicle for route administration or any other control systems. Putting aside the sustainability aspects of wireless data services over radio frequency, the issue still exists in relation to multiple parallel participants in a radio-based network can interfere and alter the reliability of the existent data links (Tsonev et al., 2013). Further, Wi-Fi penetration across walls poses a network security threat. Considering these challenges, secure faster connectivity and sus- tainable option in terms of $\mathrm{Li}$-Fi was considered by the organisation. As Li-Fi is a relatively new technology with limited applied knowledge, a number of issues relating to connection speed and reliability were experienced. The study presented here aims to identify, characterise and optimise key process input variables (KPIVs) to achieve optimum connection speed and reliability. This study was conducted in a UK-based, global technology company renowned for its end-to-end warehousing solutions. A graphical representation of how data transmission is done between AGV and System Li-Fi transceiver is shown in Fig 1. A transceiver is a device that acts as a transmitter and receiver for dual communication purposes.

With the implementation of the next generation AGV, a high failure rate due to connection speed and reliability was experienced. For AGV to be operational, key information like route-map, firmware etc. are transferred onto the system using a Li-Fi transceiver. However, $17 \%$ of AGV were failing during this stage, making them non-functional and affecting site operational efficiency severely. So far, no scientific study of this nature has been published; thus, the findings are promising in terms of revealing novel insights into how variation caused by manufacturing and installation process can be resolved using the Six-Sigma methodology.

\section{LITERATURE REVIEW}

Automated solutions are often employed by the Intralogistics industry to achieve a more flexible, reduced rate of human errors and continuous flow of goods. One of the major developments in this indus-

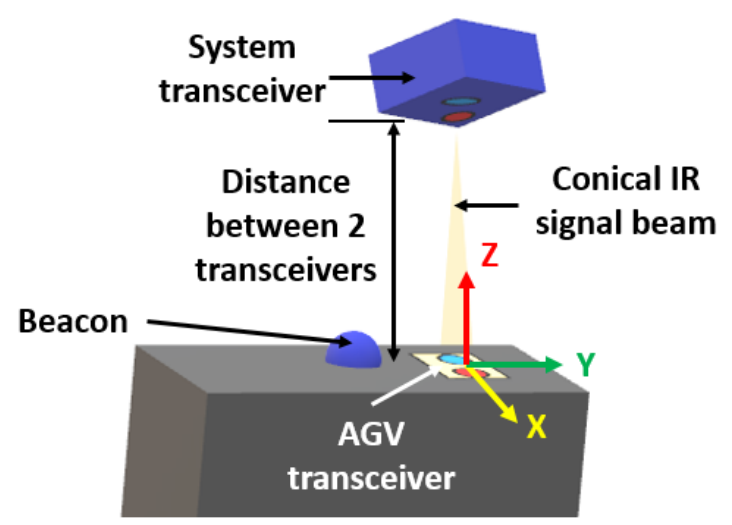

Fig. 1. Graphical representation of Li-Fi communication between system and AGV 
try has been the use of automated guided vehicles to control the flow of goods where human intervention could be impractical or cost-ineffective, e.g., working in a sub-zero chill refrigeration environment. AGV are typically connected via WLAN or other radiobased communication technologies with the vehicle for route administration or any other control systems. However, many parallel participants in a radio-based network can cause interference and affect the reliability of data links. Also, the increasing demand for wireless data communication via an available radiofrequency spectrum is running out of capacity and becoming insufficient for catering to the increased needs. Several independent warnings have been raised about the saturation of network spatial capacity despite the new technological advancements in the field of wireless communication via the RF spectrum (Ofcom, 2014). Furthermore, spatial reuse and co-channel interference are not ideal for automated solutions, especially while controlling AGV. This presents itself as a huge challenge for the wireless communication industry, thus creating an urgency to explore alternative parts of the electromagnetic spectrum which can be used to reduce strain on the already overcrowded RF spectrum (Tsonev et al., 2013).

A common substitute presented by the wireless communication industry is the use of Light-Fidelity ( $\mathrm{Li}-\mathrm{Fi})$ of an optical wireless (OW) or visible light communication (VLC) system. This is of particular interest as it is used in the study presented in this article. The VLC is a technology that includes the transmission of data through free space or fibre using wavelengths ranging from infrared (IR) to ultraviolet (UV), including visible light spectrum (Haas \& Cogalan, 2019). The Li-Fi branch of VLC is like the Wireless Fidelity (Wi-Fi) that allows electronic devices to connect wirelessly to the network. The Li-Fi system uses high-intensity light source like LED bulbs that are controlled by the driver-circuit, which encodes data and transmits it by switching the LED on and off, similar to Morse code. The only difference is that the rate at which it flicks LED on and off is indiscernible to human perception and required an optical sensor to receive/decode the data (Elgala, Mesleh \& Haas, 2011).

Research, development and standardisation of VLC were led by the Visible Light Communication Consortium (VLCC) in Japan, resulting in two visible light standards labelled as JEITA CP-1221 and JEITA CP-1222 by Japan Electronics and Information Technology Industries Association (JEITA). In 2011, IEEE
802.15.7-2011 - IEEE Standard for Local and Metropolitan Area Networks--Part 15.7: Short-Range Wireless Optical Communication Using Visible Light was also published. Comparing Li-Fi to other data communication technologies, like Wi-Fi and Ethernet, it is relatively new and came into existence during 2011. On the other hand, the Ethernet is a wellestablished LAN technology that was commercially released during 1980 as IEEE802.3. The Ethernet speed based on the latest IEEE802.3ck standard can achieve upto $100 \mathrm{~Gb} / \mathrm{s}$. Other dimensions that interested researchers are data transmission medium, security, range (10 metres for $\mathrm{Li}-\mathrm{Fi}$ and $100-185$ metres for Ethernet), reliability (high vs very high for $\mathrm{Li}-\mathrm{Fi}$ and Ethernet, respectively), connection ( $\mathrm{Li}-\mathrm{Fi}$ being wireless and Ethernet is wired) and cost ( $\mathrm{Li}-\mathrm{Fi}$ being the cheapest). Table 1 offers a systematic comparison between these three data communication technologies as presented in published literature (Elbasher, Mustafa \& Osman, 2015; Gent, Downing \& Dalton, 2003; Giuseppe et al., 2003) on these metrics.

For the study presented in this article, data communication is carried out on moving devices; thus, wireless technology was necessary. For this reason, despite all the benefits that the Ethernet LAN offers, it was not considered a good fit for this purpose. Further, security and reduced interference between cross channels gave $\mathrm{Li}-\mathrm{Fi}$ an edge over $\mathrm{Wi}-\mathrm{Fi}$. The $\mathrm{Li}-\mathrm{Fi}$ technique has a wide range of application across distinct sectors. E.g., in a research published by Sudha (2016) and during a project titled AAL X AAL by the VDA group, Li-Fi was used to enable data connectivity that does not produce electromagnetic pollution and which can potentially be detrimental to life-saving machinery like MRI scanners. A number of patient data metrics such as temperature, heartbeat, glucose and respiratory were collected using sensors and transmitted to a graphical representation on the PC. In the end, the KPI of reducing interference to medical equipment was effectively achieved. In other studies, Li-Fi was applied for improving reliability collaboration, security measures and interferencefree traffic management system (Singh et al., 2017; Wang et al., 2017). In the study by Singh et al. (2017), $\mathrm{Li}-\mathrm{Fi}$ was used to manage a vehicle toll collection system transmitter was installed on the vehicle sending encrypted data such as vehicle registration number, personal identification number and payment gateway password via LED. It helped develop a seamless automated system. Similarly, Wang (2017) created a smart transportation model, where traffic data 
Tab. 1. Comparative Summary of common data communication technologies

\begin{tabular}{|c|c|c|c|}
\hline Key Parameters & LI-FI (LIGHT FIDELITY) & WI-FI (WIRELESS FIDELITY) & ETHERNET \\
\hline IEEE Standards & 802.15 .17 & $802.11 b$ & 802.3 \\
\hline Frequency & $10 \times$ Tera $\mathrm{Hz}$ & $2.4 \mathrm{GHz}$ & $-N A-$ \\
\hline Data Transmission Medium & Light & Radiofrequency & UTP - STP - OF \\
\hline Speed & $1-3.5$ Gbps & 25-250 Mbps & 10-1000 Mbps \\
\hline Range & 10 meters & 20-100 Meters & 100 - 185 Meters \\
\hline Security & $\begin{array}{l}\text { High (direct line of sight re- } \\
\text { quired) }\end{array}$ & $\begin{array}{l}\text { Medium (can penetrate } \\
\text { through walls) }\end{array}$ & $\begin{array}{l}\text { High (physical connection } \\
\text { required) }\end{array}$ \\
\hline Reliability & High & High & Very High \\
\hline Release Date & 2011 & 1990 & 1980 \\
\hline Connection & Wireless & Wireless & Wired \\
\hline Cost & Cheapest & Most Expensive & Cheaper than Wi-Fi \\
\hline
\end{tabular}

was managed autonomously in real-time. The vehicle data relating to its speed was monitored, and the smart vehicle was controlled by the output from the traffic management system. The $\mathrm{Li}$-Fi technique exhibited tremendous potential in managing traffic with fewer accidents.

With the use of Li-Fi as an optical data transmission technology, stable interference-free data links can be set up, thus ensuring secure data transmission at all times. An additional advantage of $\mathrm{Li}$-Fi is that the parallel operation of many vehicles utilising a similar, stable bandwidth can be realised. However, not much evidence was found on the use of IR based Li-Fi system and how to optimise or improve connection and data transfer speed. The key issue of investigation in the current research was of high variation in the connection speed and poor reliability amongst AGV. To resolve this problem, the Six-Sigma technique was employed as statistically proven to be valid and objective. Key elements of the Six-Sigma DMAIC (Define, Measure, Analyse, Improve, and Control) methodology were applied to resolve the issue of high failures due to low connection speed and poor reliability between two Li-Fi transceivers. The problem statement for the current project was that $17 \%$ of AGV were failing to connect at XX (confidential) site using Li-Fi that was further resulting in a strain on the bottleneck process. The overall aim of this research was to reduce AGV connection failures due to Li-Fi connection speed and reliability.

Specific research objectives:

- To identify the factors responsible for high connection failure rates.

- To characterise and optimise KPIVs to achieve optimum connection speed and reliability.

- To implementing sustainable long-term process improvements that will reduce the defect rate to $<1 \%$.

\section{RESEARCH METHODS}

An experimental research design with an inherent manipulation of the experimental variables was adopted in the current research. Six Sigma is a quality improvement technique that has been shown to be scientific, rigorous, and systematic. It is based on the careful integration of a range of statistical methods that enables new developments and error reduction in existent phenomenon (Breyfogle et al., 2001). The range of benefits that implementation of the Six-Sigma methodology yields can be mapped along economic, individual, and organisational dimensions as it optimises resource usage, enhances user experience, and elevates the skill repertoire of the person in charge (Su \& Chou, 2008; Yang \& Hsieh, 2009). Supporting evidence for the excellence of the SixSigma technique has been demonstrated by several industries, such as chemical (Doble, 2005), manufacturing (Gangidi, 2019; Sharma, Sahni \& Sharma, 2020), financial (Brewer \& Eighme, 2005), information technology (Arul \& Kohli, 2004; Edgeman, Bigio \& Ferleman, 2005), automobile (Gerhorst et al., 2006), and senior administration (Furterer \& Elshennawy, 2005).

A team of qualified technical staff was gathered for the implementation of the technical aspects of this project, and a certified Six-Sigma black belt specialist was appointed for overlooking the implementation of the Six-Sigma framework. A Six-Sigma process of DMAIC, based on Deming's Plan-Do-Check-Act cycle for improving existent processes, was selected for this study. The DMAIC strategy consists of five stages: Define, Measure, Analyse, Improve, and Control.

Define is the first and foremost stage which involves operationalisation of the project's objectives and delineation of critical to quality (CTQ). The 
CTQs are formulated in strict accordance with customers' preferences.

Measure stage consists of data collection and a systematic assessment of the key components of the project plan.

Analyse phase is concerned with statistical evaluation of trends in data and serves as pilot testing results that facilitates future replications of valid and quantifiable models.

Improve is the implementation patch which aims at completing the set objectives and achieving the desired benefits.

Control refers to documentation of every single detail of the previous so that successful episodes would serve as guidelines while failures would provide insights into potentially fraught procedures for effective planning and monitoring of future projects.

\section{RESEARCH RESULTS}

This section presents key outcomes from the DMAIC phases of the improvement project with an enhanced focus on the Analyse and Improve phases. At the completion of the Define and Measure phases, "connection speed" was identified as a Key Performance Indicator (KPI) and KPIVs that can affect connection speed are shown using a Fishbone Diagram in Fig. 2.
Post segregation, it was identified that the failure rate was considerably higher for the next generation AGV. So, gaining an understanding of the differences between those two AGV emerged as a top priority for future investigation. The KPIV list from the Fishbone Diagram was narrowed down to 6 factors. L36 $\left(2^{\wedge} 3,3 \wedge 3\right)$ Taguchi Design of Experiment (DoE) was deemed appropriate to evaluate the impact of KPIVs on connection speed with the CNX diagram shown in Fig. 3.

Further understanding into alignment/position experimental variables (X, Y \& Z-pos) can be gained from Fig. 1 of the introduction section. To achieve different levels of experimental variables for the DoE was straightforward except the vibration due to the unavailability of the measurement system. To overcome this challenge, two levels of vibration were selected. Firstly, when no AGV were operational, producing negligible vibration, and secondly, when multiple AGV were running around the test set-up. With the test set-up confirmed, Taguchi DoE was conducted, and the main effects plot for the mean connection speed are shown in Fig. 4. Key factors influencing connection speed were the positions (X, $\mathrm{Y}, \mathrm{Z}$ Pos) or an alignment between the two $\mathrm{Li}-\mathrm{Fi}$ transceivers along with AGV type. The impact of each factor on connection speed is inferred from the "delta" (Table 2), based on which they are rankordered. The key difference between the two AGV was the installation position of the $\mathrm{Li}-\mathrm{Fi}$ transceiver.

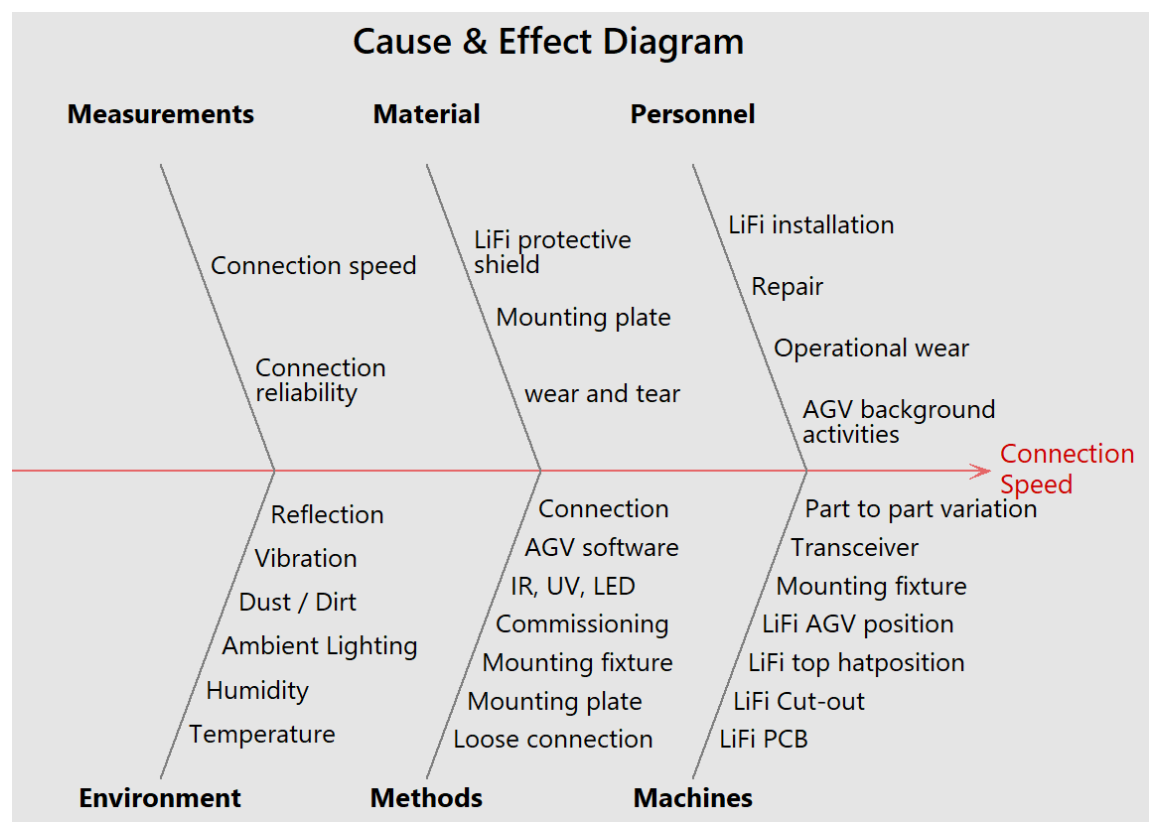

Fig. 2. Fishbone Diagram for connection speed 
After gaining relevant insights from the Taguchi DoE, the next set of experimental designs were focused on the Li-Fi position and aimed at making designs more resilient to the $\mathrm{Li}$ - $\mathrm{Fi}$ installation position on the AGV. As Z-pos or distance between the transceivers was the most important factor, the optimum setting without interaction were found to be $240 \mathrm{~mm}$ via One Factor At a Time (OFAT) testing. The next set of tests were conducted to evaluate the impact of surface reflection, AGV type and Cut-Out Size on connection speed in conditions where $\mathrm{X}, \mathrm{Y}$ position is perfectly aligned, and Z-position is fixed at $240 \mathrm{~mm}$. A full factorial design with 3 factors and 2 levels was conducted with the Main Effects Plot. The model summary is shown in Fig. 5 and Table 3, respectively. It is evident that in cases where the $\mathrm{Li}-\mathrm{Fi}$ position is at an optimum position, none of the other factors had a statistically significant impact on the connection speed. Moreover, R-sq (adj) for the model is zero and the $\mathrm{p}$-value for all the factors is $<0.05$.

Reflecting on the analysis conducted so far, it can be argued that the optimum connection speed could be achieved by controlling the Li-Fi position. However, the margin for error was only $\pm 5 \mathrm{~mm}$ in $\mathrm{X}-\mathrm{Y}$ alignment, which was difficult to achieve consistently during the installation and operation processes. So, the next set of experiments included X, Y, Z-pos and cut-out size to identify the tolerance for the $\mathrm{X}, \mathrm{Y} \& \mathrm{Z}$ positions. Additionally, a 4 factor 2 level Full Factorial DoE with centre points was conducted with the main effects plot. The model summary is shown in Fig. 6 and Table 4, respectively.

A strong regression model with R-sq(Adj) of 90.61\% was achieved with a combination of four factors tested during the experiment suggesting most of the process variation can be controlled via these fac-

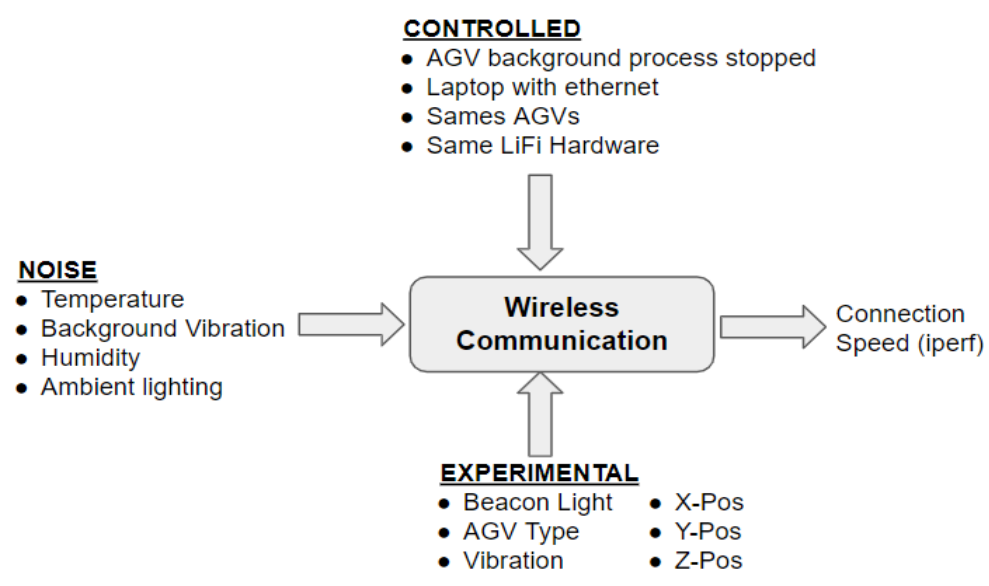

Fig. 3. CNX diagram for Taguchi DoE

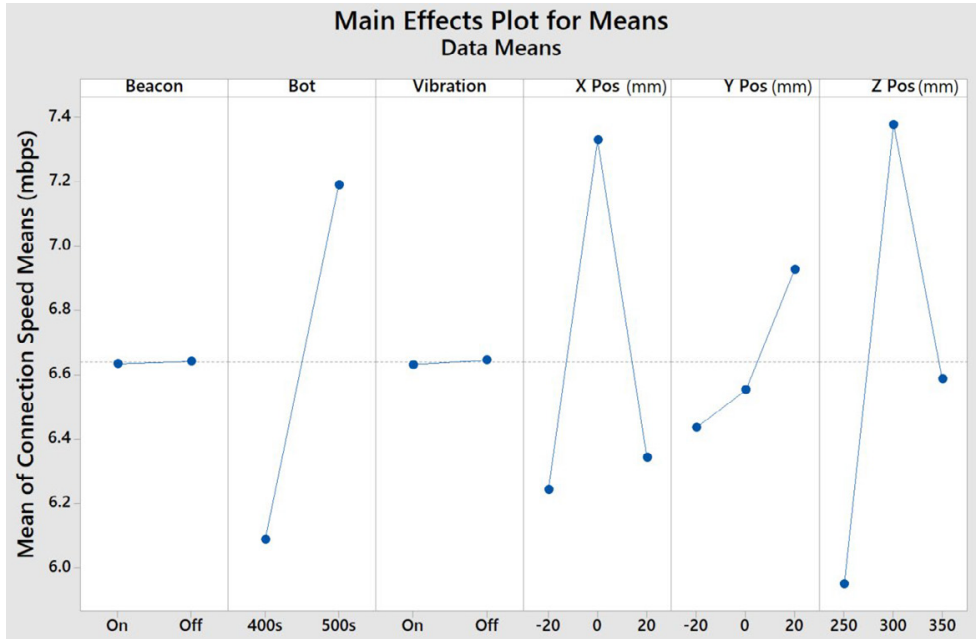

Fig. 4. Main effects plot for mean connection speed 
Tab. 2. Response table for mean connection speed (in mbps)

\begin{tabular}{|c|r|r|r|r|r|r|}
\hline LEVEL & \multicolumn{1}{|c|}{ BEACON } & \multicolumn{1}{c|}{ AGV } & \multicolumn{1}{c|}{ VIBRATION } & \multicolumn{1}{c|}{ X POS } & \multicolumn{1}{c|}{ Y POS } & Z POS \\
\hline 1 & 6.634 & 6.088 & 6.632 & 6.243 & 6.437 & 5.951 \\
\hline 2 & 6.642 & 7.190 & 6.646 & 7.329 & 6.553 & 7.378 \\
\hline 3 & & & & 6.344 & 6.927 & 6.587 \\
\hline Delta & 0.008 & 1.102 & 0.014 & 1.087 & 0.490 & 1.426 \\
\hline Rank & 6 & 2 & 5 & 3 & 4 & 1 \\
\hline
\end{tabular}

Tab. 3. Model summary and coded co-efficient for the connection speed

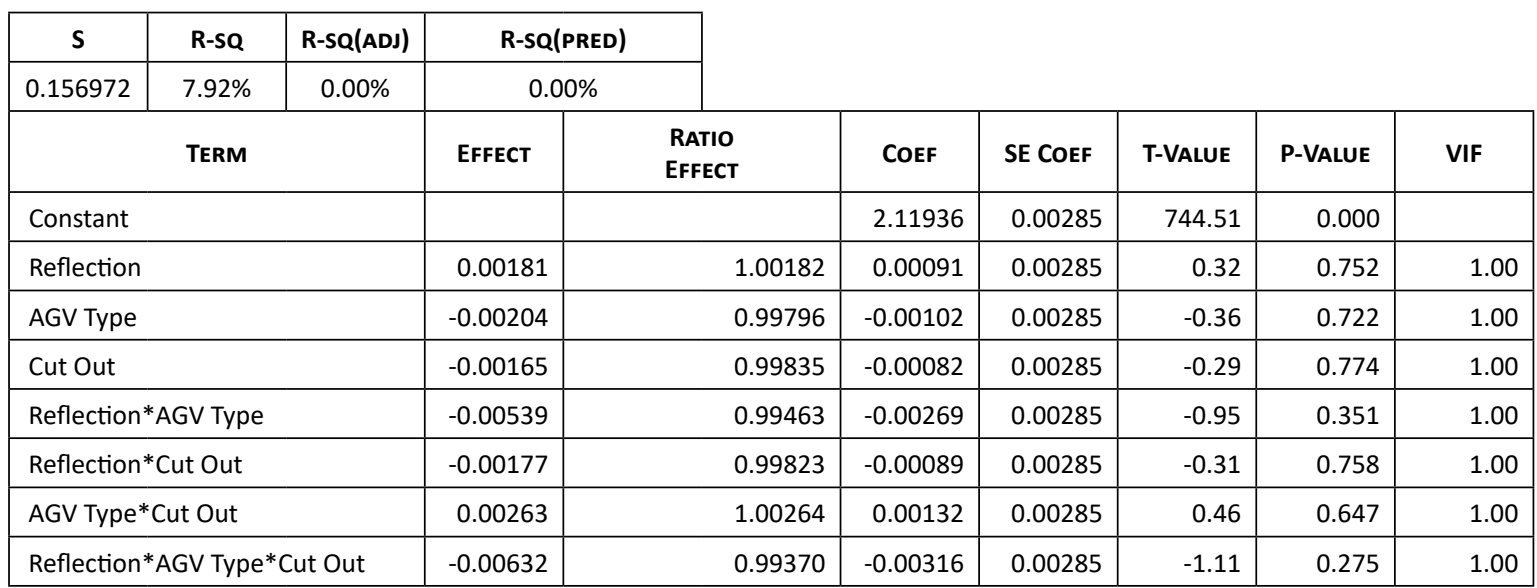

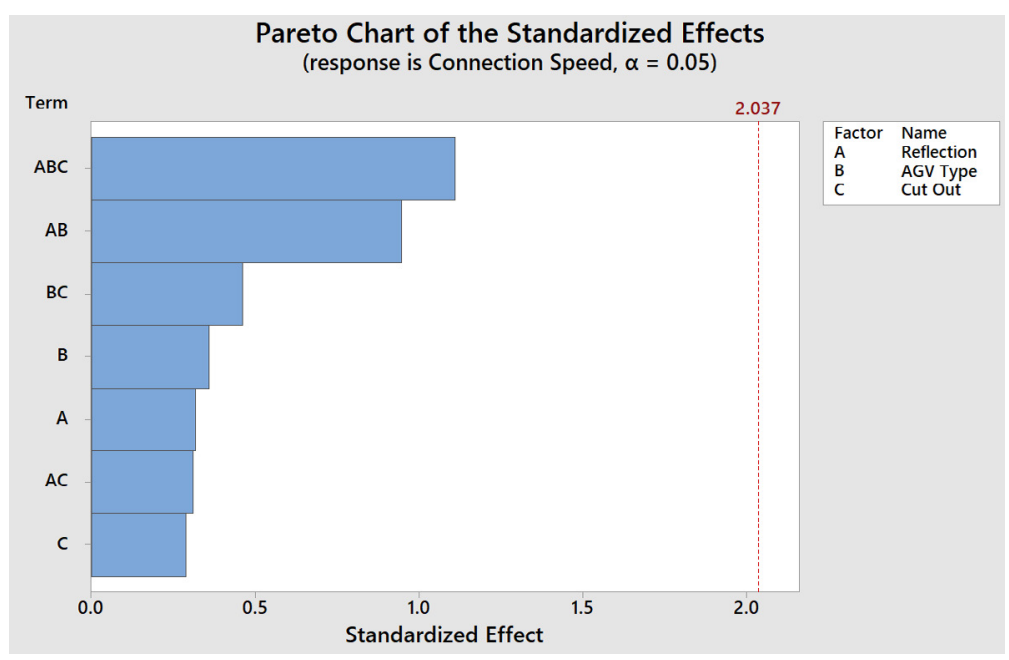

Fig. 5. Pareto chart of the standardised effect

tors. It was calculated (using the response optimiser of Minitab) that by introducing a cut-out, the alignment tolerance for the $\mathrm{X}, \mathrm{Y}$ and $\mathrm{Z}$ position can be increased from $10 \mathrm{~mm}$ to $40 \mathrm{~mm}$ prior to obtaining a statistically significant change in the connection speed.

Increased tolerance in position was enough to accommodate manufacturing, installation and operational variations between the two AGV. The introduction of a bigger opening (cut-out) to receive and send a signal provided a robust design. Following parameters were used for an optimum set-up:
- Bigger Cut-Out

- $\mathrm{X}$-Pos $=-30$ to $10 \mathrm{~mm}$

- $\mathrm{Y}$-Pos $=-10$ to $30 \mathrm{~mm}$

- Z-Pos $=220$ to $260 \mathrm{~mm}$

Pilot testing was conducted on this set-up using a single Li-Fi set-up but multiple AGV. Process capability, $\mathrm{Cpk}=3.18$, was much higher than the industry standard of 1.67, which suggested the robustness of the solution.

The new set-up has been rolled out to the entire site with over $20 \mathrm{Li}-\mathrm{Fi}$ set-ups and hundreds of AGV. It has been running for over three months, with 
Tab. 4. Model summary and coded co-efficient for Connection speed

\begin{tabular}{|c|c|c|c|c|c|c|}
\hline S & R-sQ & $R-S Q(A D J)$ & \multicolumn{2}{|c|}{ R-SQ(PRED) } & & \\
\hline 0.929010 & $91.56 \%$ & $90.61 \%$ & \multicolumn{2}{|c|}{$88.99 \%$} & & \\
\hline TERM & EFfECt & COEF & SE COEF & T-VALUE & P-Value & VIF \\
\hline Constant & & 5.579 & 0.147 & 37.98 & 0.000 & \\
\hline AGV Cut-Out & -3.992 & -1.996 & 0.120 & -16.64 & 0.000 & 1.00 \\
\hline Height & -0.757 & -0.378 & 0.147 & -2.58 & 0.013 & 1.00 \\
\hline$X$ Pos & -0.720 & -0.360 & 0.147 & -2.45 & 0.018 & 1.00 \\
\hline Y Pos & 3.702 & 1.851 & 0.147 & 12.60 & 0.000 & 1.00 \\
\hline Cut-Out*Y Pos & 2.860 & 1.430 & 0.147 & 9.74 & 0.000 & 1.00 \\
\hline $\mathrm{Ct} P \mathrm{Pt}$ & & 1.436 & 0.254 & 5.64 & 0.000 & 1.00 \\
\hline
\end{tabular}

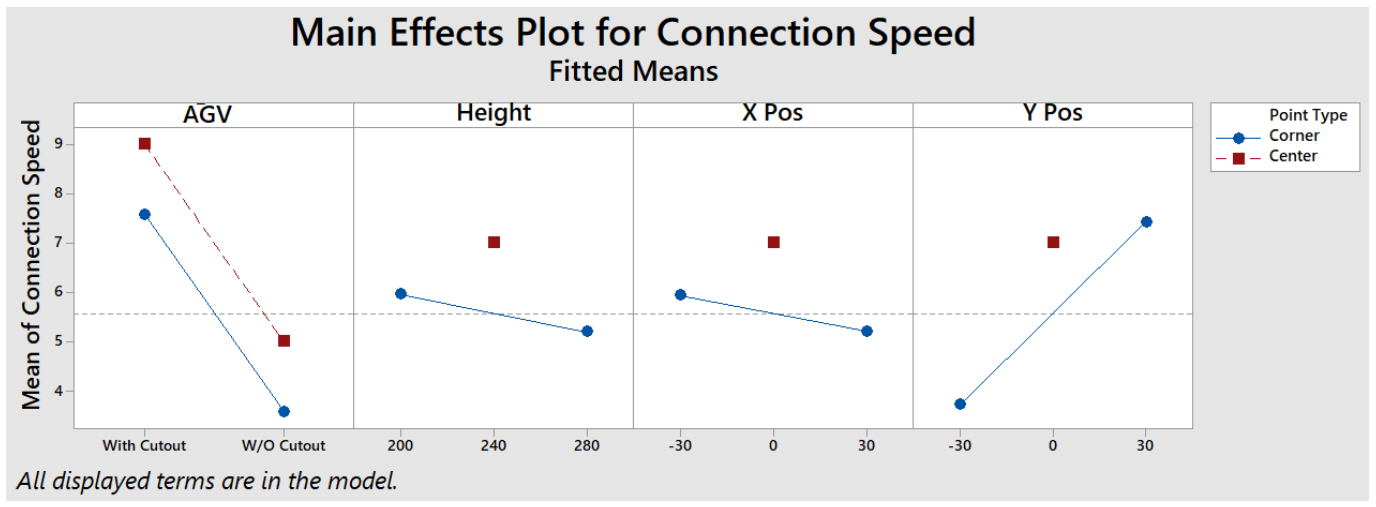

Fig. 6. Main effects plot for mean connection speed

Process Capability Report for Connection Speed

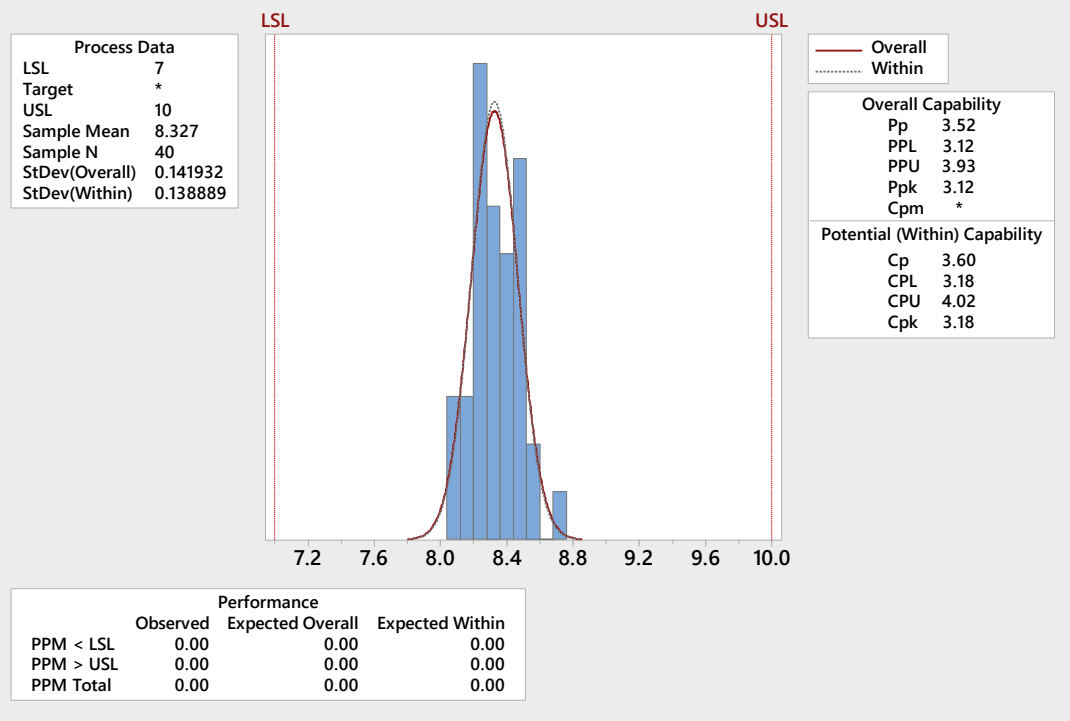

Fig. 7. Process capability of pilot testing 
approx. of 4500 operations and zero connection failures observed so far.

\section{DISCUSSION OF RESULTS}

The research study presented in this article was successful in meeting all the set objectives. The failure rate occurring due to a loss of connection was reduced from $17 \%$ to $0 \%$ while maintaining a good process capability of 3.18. The current research paper aimed at the identification, characterisation and optimisation of the key input variables to achieve a robust solution. It is already known (Tsonev et al., 2013; Le Bas et al., 2015) that an alignment between two transceivers is crucial for the establishment of a reliable and high connection speed. However, published scientific literature did not reveal any details about the extent of a misalignment tolerated prior to its significant impact on connection speed. This gap in research could be attributed to the design's dependence on the Li-Fi product type (technology used) and application. Thus, a characterisation of the impact of Li-Fi transceiver alignment for the products used in the current study was of high relevance. It was found that the distance between two transceivers, when set at 240 $\pm 20 \mathrm{~mm}$, could accommodate misalignment of $\pm 5 \mathrm{~mm}$ on the X \& Y-axis without compromising the connection speed.

Another interesting finding from the current research was that an increase in the surface area that received and transmitted signal (cut-out) was critical for achieving a robust design that could deal with a higher tolerance for misalignment. In cases where the two transceivers were perfectly aligned, a bigger cut-out had no impact. However, in the current application, a misalignment between two transceivers could be as high as $20 \mathrm{~mm}$ due to operating and manufacturing variation. Thereby an increase in the cut-out, and with a $\pm 20 \mathrm{~mm}$ misalignment, the connection speed and reliability remained unaffected.

Other research studies (Pradhan, Kappala \& Das, 2020; Sharma, Sanganal \& Pati, 2014) have found that the communication channel may suffer from interferences caused by the ambient lighting conditions. A finding of great relevance was that the Li-Fi transceiver used in the current design remained unaffected by the visible ambient lighting even when placed in close proximity to the $\mathrm{Li}-\mathrm{Fi}$ unit. It should also be noted that the product used in the current application is an infrared Li-Fi transceiver and not a LED version that has been cited as a potential cause of this devia- tion from the previously published research studies. Furthermore, since IR lighting is not used at this site, it wasn't considered necessary to evaluate its impact on signal interference.

Additionally, it should be noted that planning and administration of confirmation testing, and a pilot run after performing experimental design, especially screening tests, is strongly recommended. Supporting evidence for this recommendation is derived not only from the current research but from previously published literature as well (Sreedharan et al., 2019; Sharma, Sahni \& Sharma, 2019). In the current experimental testing, ineffective results with no impact on the failure rates were observed, on the implementation of a pilot run that was based on the results from Taguchi screening DoE. The only promising insight gathered through the pilot run was of finding significant input variables. However, the inability to detect a significant interaction between the newly identified factors resulted in a non-optimum set-up. The next stage DoE was administered to characterise the key process input variables and their interactions. This aided in the creation of a significant regression model that resulted in an optimum set-up. Following this, another confirmation test and pilot experiments were conducted to validate the results. The significance of conducting a confirmation test and pilot experiments is, therefore, further endorsed by the current research results.

The issue of recurring failures was effectively prevented by the implementation of the Six-Sigma methodology, which further strengthens the current evidence on the wide scope of the Six-Sigma methodology in manufacturing operations (Swarnakar \& Sekar, 2016; Sharma, Sahni \& Sharma, 2019a). The issue of recurring connection failures was identified to be a constant source of restrictive strain on the bottleneck process, thereby resulting in a huge financial cost to the company and very high dissatisfaction amongst the users. The current research strategy, based on the Six-Sigma methodology, resulted in complete elimination of the failures occurring due to connection problems. Moreover, the current set-up has been running for a few months now, and no more cases of previously recurring failures have been observed since the implementation of the optimum set-up.

The current study did not explore the issue of interference in the communication channel caused by infra-red (IR) or ultraviolet lighting (UV), as not even a single source of IR/UV lighting was present in the close proximity of a $\mathrm{Li}-\mathrm{Fi}$ unit. However, it is 
strongly recommended that the issues of interference be checked and controlled for in other applications, where their sources might be present. Secondly, the two levels of vibration ( On \& Off) were controlled by oscillating the normal site operation between the functions of on and off. Future research can perhaps measure and control this vibration using a vibration bed to evaluate and characterise it against the connection speed.

\section{CONCLUSIONS}

The study presented in this article was aimed at reducing high failures due to connection issues using a specific IR-based Li-Fi transceiver in the logistics industry. The failures due to connection issues were completely eliminated with the implementation of a robust solution. Alignment and distance between the two transceivers were the most critical factors affecting the connection speed. The Li-Fi surface area to send and receive signal proved to be critical for delivering an effective solution that can deal with higher positional variation. All these factors were successfully identified, characterised and optimised using the Six-Sigma methodology. Li-Fi is an emergent wireless communication technology that has found application in a wide variety of industries. Once the connection speed issue was resolved, $\mathrm{Li}-\mathrm{Fi}$ performed exceptionally well in providing an interference-free and secure connection between moving objects.

\section{LITERATURE}

Arul, K., \& Kohli, H. (2004). Six-sigma for software application of hypothesis tests to software Data. Software Quality Journal, 12(1), 29-42.

Brewer, P., \& Bagranoff, N. A. (2004). Near zero-defect accounting with six-sigma. Journal of Corporate Accounting \& Finance (Wiley), 15(2), 67-43.

Breyfogle, F. W., Cupello, J. M., \& Meadows, B. (2001). Managing six-sigma: a practical guide to understanding, assessing, and implementing the strategy that yields bottom-line success. New York, United States: Wiley.

Cisco (2019). Cisco Visual Networking Index: Forecast and Trends, 2017-2022 White Paper, Cisco Forecast and Methodology. Retrieved from http://www.cisco. com/en/US/solutions/collateral/ns341/ns525/ns537/ ns705/ns827/white_paper_c11-481360_ns827_Networking_Solutions_White_Paper.html

Doble, M. (2005). Six-sigma and chemical process safety. International Journal of Six-sigma and Competitive Advantage, 1(2), 229-244.
Edgeman, R., Bigio, D., \& Ferleman, T. (2005). Six-sigma and business excellence: strategic and tactical examination of IT service level management at the office of the chief technology officer of Washington, DC. Quality and Reliability Engineering International, 21(3), 257-273.

Elbasher, W. S. M., Mustafa, A. B. A., \& Osman, A. A. (2015). A Comparison between $\mathrm{Li}-\mathrm{Fi}, \mathrm{Wi}-\mathrm{Fi}$, and Ethernet Standards, International Journal of Science and Research (IJSR), 4(12), 1-4.

Elgala, H., Mesleh, R. \& Haas, H. (2011). Indoor Optical Wireless Communication: Potential and State-ofthe-Art. IEEE Communications Magazine, 49(9), 56-62. doi: 10.1109/MCOM.2011.6011734

Furterer, S., \& Elshennawy, A. (2005). Implementation of TQM and lean six-sigma tools in local government: a framework and a case study. Total Quality Management and Business Excellence, 16(10), 1179-1191.

Gangidi, P. R. (2019). Application of Six Sigma in Semiconductor Manufacturing: A Case Study in Yield Improvement, Applications of Design for Manufacturing and Assembly. Ancuţa Păcurar, IntechOpen. doi: 10.5772/intechopen.81058

Gent, G. P., Downing, C., \& Dalton, J. (2003). Comparative Performance of Wireless and Powerline LANs for Streaming Media. Retrieved from http://www. citeseerx.ist.psu.edu

Gerhorst, F., Grömping, U., Lloyd-Thomas, D., \& Khalaf, F. (2006). Design for six-sigma in product development at Ford Motor Company in a case study on robust exhaust manifold design. International Journal of Product Development, 3(3/4), 278-291.

Giuseppe A., Eleonora B., Marco C., \& Enrico, G. (2003). IEEE 802.11b Ad Hoc Networks: Performance Measurements. Proceedings of the 23 rd International Conference on Distributed Computing Systems Workshops (ICDCSW`03), 758-763.

Haas, H. (2018). LiFi is a paradigm-shifting $5 \mathrm{G}$ technology, Reviews in Physics, 3, 26-31. doi: 10.1016/j.revip.2017.10.001

Haas, H., \& Cogalan, T. (2019). LiFi Opportunities and Challenges. In International Symposium on Wireless Communication Systems. 16th International Symposium on Wireless Communication Systems, Oulu, Finland.

Le Bas, C., Sahuguede, S., Julien-Vergonjanne, A., Behlouli, A., Combeau, P., \& Aveneau, L. (2015). Impact of receiver orientation and position on Visible Light Communication link performance. 4th International Workshop on Optical Wireless Communications (IWOW), Istanbul, 1-5. doi: 10.1109/ IWOW.2015.7342254

Ofcom, (2014). Study on the future UK spectrum demand for terrestrial mobile broadband applications, real wireless, Version 3.1. Retrieved from https://www.ofcom.org.uk/_data/assets/pdf_file/0016/51235/rw_report.pdf

Pradhan, J., Kappala, V. K., \& Das, S. K. (2020). Performance Analysis of a Li-Fi System under Ambient Light Conditions, 2020 National Conference on Communications (NCC), Kharagpur, India, 1-6. doi: 10.1109/NCC48643.2020.9056061

Sharma R. R., Sanganal, A. \& Pati, S. (2014). Implementation of A Simple Li-Fi Based System. IJCAT - Inter- 
national Journal of Computing and Technology, 1(9), 437-443.

Sharma, M., Sahni, S. P., \& Sharma, S. (2019). Reduction of defects in the lapping process of the silicon wafer manufacturing: the Six Sigma application. Engineering Management in Production and Services, 11(2), 87-105. doi: 10.2478/emj-2019-0013

Sharma, M., Sahni, S. P., \& Sharma, S. (2019a). Validating a destructive measurement system using Gauge R\&R - A case study, Engineering Management in Production and Services, 11(4), 34-42. doi: 10.2478/ emj-2019-0031

Sharma, M., Sharma, S., \& Sahni, S. (2020). Structured Problem Solving - Combined Approach using 8D and Six Sigma Case Study. Engineering Management in Production and Services, 12(1), 57-69. doi: 10.2478/emj-2020-0005

Singh, D., Sood, A., Thakur, G., Arora, N., \& Kumar, A. (2017). Design and implementation of wireless communication system for toll collection using LIFI. 4th IEEE Int. Conf. Signal Process. Comput. Control. ISPCC 2017-Janua, 510-515.

Sreedharan, R. V., Raju, R., Vijaya Sunder, M., \& Jiju, A. (2019). Assessment of Lean Six Sigma Readiness (LESIRE) for manufacturing industries using fuzzy logic. International Journal of Quality \& Reliability Management, 36(2), 137- 161. doi: 10.1108/ IJQRM-09-2017-0181

$\mathrm{Su}$, C. T., \& Chou, C. J. (2008). A systematic methodology for the creation of six-sigma projects: A case study of semiconductor foundry. Expert Systems with Applications, 34, 2693- 2703.

Sudha, S., Indumathy, D., Lavanya, A., Nishanthi, M., Sheeba, D. M., \& Anand, V. (2016). Patient monitoring in the hospital management using Li-Fi. 2016 IEEE Technological Innovations in ICT for Agriculture and Rural Development (TIAR), 93-96.

Sumits, A. (2015). The History and Future of Internet Traffic, Cisco Blogs. Retrieved from https://blogs.cisco. $\mathrm{com} / \mathrm{sp} /$ the-history-and-future-of-internet-traffic

Swarnakar, V., \& Sekar, V. (2016). Deploying Lean Six Sigma framework in an automotive component manufacturing organization. International Journal of Lean Six Sigma, 7(3), 267-293.

Tsonev, D., Videv, S., \& Haas, H. (2013). Light Fidelity (LiFi): Towards All-Optical Networking. Edinburgh, UK: Institute for Digital Communications, Li-Fi R\&D Centre, The University of Edinburgh.

Wang, N., Liu, C., Lu, Y., \& Shen, J. (2017). A Visible Light Communication (VLC) based Intelligent Transportation System for Lorry Fleet. 16th International Conference on Optical Communications and Networks (ICOCN), 16-18.

Yang, T., \& Hsieh, C. H. (2009). Six-sigma project selection using national quality award criteria and Delphi fuzzy multiple decision-making method. Expert Systems with Applications, 36, 7594-760. 